\title{
Antireflexivization as a Causativization Strategy
}

\author{
Bonnie Krejci \\ Stanford University
}

\section{Introduction}

This paper is concerned with the causativization pattern of transitive verbs that denote actions of eating and drinking (ingestives), and verbs that denote self-directed action, like wash, dress, shave, and bathe (middles). In some languages, these verbs causativize as though they were intransitive (Shibatani, 2002). Middle verbs have been analyzed as reflexives (Kemmer, 1993), which could explain why they do not always pattern with canonical transitives. I argue that ingestives can be analyzed in a similar way, as lexically reflexive, with internally complex event structures. I show that these classes of verbs have analogous meaning differences between their lexical and periphrastic causative variants, suggesting that the two types of causatives are derived from the basic variants via different operations. Instead of being derived by causer addition, lexical causatives may be derived via an antireflexivization operation that delinks two co-indexed arguments in the verb's event structure.

\section{Lexical Entailments of Middles and Ingestives}

I argue against a simple representation of eat as shown in (1), and its causative variant, formed via causer addition, in (2), because these representations make incorrect predictions about the lexical entailments of the causative variants. ${ }^{1}$

(1) eat: $\left[\mathrm{ACT}_{\langle\text {potentially digest }\rangle}(\mathrm{x}, \mathrm{y})\right]$

(2) feed/make eat: $\left[[\operatorname{ACT}(\mathrm{x})] \operatorname{CAUSE}\left[\operatorname{ACT}_{\langle\text {potentially digest }\rangle}(\mathrm{y}, \mathrm{z})\right]\right]$

Middles and ingestives have significant meaning differences between their lexical and periphrastic causative variants, and those differences are analogous for both classes of verbs. The basic variant (e.g. eat, intransitive dress) has a set of lexical entailments that are required of the subject participant. In a periphrastic causative construction, that set of entailments still holds of the causee. Crucially, with a lexical causative, that set of lexical entailments no longer holds of the causee, instead being shifted to the causer. For example, in (3a) and (3b), John is required to agentively manipulate food. In (3c), agentive manipulation of food is not entailed of John but instead of Mary. An analogous pattern exists for dress (4).

(3) a. John ate.

Basic

b. Mary made John eat.

c. Mary fed John.

Periphrastic causative

Lexical causative

(4) a. John dressed.

Basic

b. Mary made John dress.

c. Mary dressed John.

Periphrastic causative

Lexical causative

These meaning differences suggest that the operation that forms a periphrastic causative from the basic variant (i.e., causer addition) is not the same operation that yields a lexical causative.

\footnotetext{
${ }^{1}$ The lexical semantic structures throughout are in the style of Rappaport Hovav and Levin (1998).
} 
I argue that we can account for the differences in the meanings of the lexical and periphrastic causatives only by revising the representations given in (1) and (2).

\section{Bieventive Lexical Structures}

I propose that the basic forms of middles and ingestives are lexically reflexive, with bieventive, causative event structures, as in (5). Importantly, the agent and patient arguments are coidentified.

(5) a. eat: $\left[\left[\mathrm{ACT}_{\langle\text {manipulate }\rangle}(\mathbf{x}, \mathrm{y})\right] \operatorname{CAUSE}\left[\mathrm{ACT}_{\langle\text {potentially digest }\rangle}(\mathbf{x}, \mathbf{y})\right]\right]$

b. $\operatorname{dress}_{\text {intr }}:\left[\operatorname{ACT}_{\langle\text {manipulate }\rangle}(\mathbf{x}, \mathrm{y})\right]$ CAUSE $[\operatorname{BECOME}\langle$ dressed $\left.\rangle(\mathbf{x})]\right]$

When these verbs are lexically causativized, the arguments are delinked, or antireflexivized, and no longer need to co-refer, as in (6).

(6) a. feed: $\left[\left[\mathrm{ACT}_{\langle\text {manipulate }\rangle}(\mathbf{x}, \mathrm{y})\right] \operatorname{CAUSE}\left[\mathrm{ACT}_{\langle\text {potentially digest }\rangle}(\mathbf{z}, \mathrm{y})\right]\right]$

b. $\operatorname{dress}_{t r}:\left[\left[\mathrm{ACT}_{\langle\text {manipulate }\rangle}(\mathbf{x}, \mathbf{y})\right] \operatorname{CAUSE}[\operatorname{BECOME}\langle\right.$ dressed $\left.\rangle(\mathbf{z})]\right]$

These representations straightforwardly capture the fact that the entailments that hold of the subject of the basic variant hold of the causer of the lexical causative, and not of the causee. In contrast, the periphrastic causative is formed via causer addition, which preserves the entailment pattern of the basic variant because two of the arguments are co-identified, as in (7).

(7) a. make eat:

[ $\left.[\mathrm{ACT}(\mathrm{x})] \mathrm{CAUSE}\left[\left[\mathrm{ACT}_{\langle\text {manipulate }\rangle}(\mathbf{y}, \mathbf{z})\right] \operatorname{CAUSE}\left[\mathrm{ACT}_{\langle\text {potentially digest }\rangle}(\mathbf{y}, \mathbf{z})\right]\right]\right]$

b. make dress:

$\left[[\operatorname{ACT}(\mathrm{x})] \operatorname{CAUSE}\left[\left[\operatorname{ACT}_{\langle\text {manipulate }\rangle}(\mathbf{y}, \mathbf{z})\right] \operatorname{CAUSE}[\operatorname{BECOME}\langle\right.\right.$ dressed $\left.\left.\rangle(\mathbf{y})]\right]\right]$

\section{Evidence from Sublexical Modification}

Sublexical modification tests, originating from Dowty (1979), support the position that the basic variants encode complex, causative event types. If a verb has complex internal structure, it should show ambiguities with certain modifiers, such as postverbal again (Dowty, 1979; Beck \& Johnson, 2004). Verbs like eat (8) and dress (9) show the relevant ambiguity, suggesting that they are internally complex.

(8) Context: Two people are playing a video game where an avatar eats coins. They lose the level and play it again.

Your avatar ate the coin again.

a. The coin had been eaten before.

restitutive

b. Your avatar had eaten the coin before.

repetitive

(9) John dressed again.

a. John had been wearing clothes before. restitutive

b. John had dressed before.

repetitive

Similarly, sublexical modification with almost also produces ambiguities with verbs that have complex internal structures. Eat (10) and dress (11) show the relevant ambiguities.

(10) John almost ate the pie. 
a. He almost started eating the pie, but he ended up eating none of it.

b. He ate part of the pie, but just a tiny pinch of the crust.

(11) John almost dressed.

a. He almost started to dress himself, but then he didn't.

b. He started to dress himself, but he just got his socks on.

Both of these diagnostics suggest that the basic variants of eat and dress encode internally complex events.

\section{Evidence from Negation}

The lexical structures presented above make different predictions about what happens when the basic variant is negated while the lexical causative variant is asserted (see Koontz-Garboden, 2009). First, notice that it is possible to assert a feeding event and deny an eating event, without being contradictory (12).

(12) Context: A prisoner is forced to eat a meal against his will.

I didn't eat a meal, you fed a meal to me!

If eat has a simple lexical structure, as in (1), and causativization is just causer addition, as in (2), then (12) should yield a contradiction: it would mean something like (13). ${ }^{2}$

$$
\begin{aligned}
& \neg\left[\mathrm{ACT}_{\langle\text {potentially digest }\rangle}(\mathrm{I}, \text { a meal })\right] \\
& \&\left[[\mathrm{ACT}(\mathrm{you})] \mathrm{CAUSE}\left[\mathrm{ACT}_{\langle\text {potentially digest }\rangle}(\mathrm{I}, \text { a meal })\right]\right]
\end{aligned}
$$

On the other hand, if eat has a lexically reflexive bieventive structure, as in (5a), and feed is formed via antireflexivization, as in (6a), then denying an eating event while asserting a feeding event will not be contradictory, as in (14).

$$
\begin{aligned}
& \left(\neg\left[\left[\mathrm{ACT}_{\langle\text {manipulate }\rangle}(\mathrm{I}, \text { a meal })\right] \mathrm{CAUSE}\left[\mathrm{ACT}_{\langle\text {potentially digest }\rangle}(\mathrm{I}, \text { a meal })\right]\right]\right) \\
& \&\left[\left[\mathrm{ACT}_{\langle\text {manipulate }\rangle}(\mathrm{you}, \mathrm{a} \text { meal })\right] \operatorname{CAUSE}\left[\mathrm{ACT}_{\langle\text {potentially digest }\rangle}(\mathrm{I}, \text { a meal })\right]\right]
\end{aligned}
$$

The negated sentence in (12) is using logical, not metalinguistic negation (Horn, 1985). Inserting an NPI under the scope of the negation is only possible if logical negation is involved, and it is possible here (15-16).

(15) I didn't eat a meal, you fed a meal to me!

a. ? I didn't eat any meal; you fed a meal to me!

b. I didn't eat a meal at all; you fed a meal to me!

c. I don't ever eat crackers; you always feed crackers to me!

(16) I didn't dress; you dressed me!

a. I didn't dress at all; you dressed me!

b. I don't ever dress; you (always) dress me!

The fact that these logically negated sentences are non-contradictory suggests that a bieventive representation is appropriate.

\footnotetext{
${ }^{2}$ The event templates used here are not logical representations, so it is somewhat inappropriate to use the logical negation symbol $\neg$. We can think of the event templates as corresponding to elements of the logical structure of the verb, and assume that the negation symbol negates the lexical entailments introduced by the corresponding structure.
} 


\title{
6 Evidence from Modification with by itself
}

Chierchia (2004) proposes that the Italian modifier da sé "by itself" can mean "without outside help" only when there is cause in the meaning of the verb. Extending this to English, eat and dress both accept modification with all by itself on the "without outside help" reading, and no repair reading is necessary.
a. The girl ate her food all by herself.
b. The girl dressed all by herself.

\begin{abstract}
"without outside help"/"alone"
"without outside help"/"alone"
\end{abstract}

\section{Conclusions}

Evidence from sublexical modification, negation, and the by itself test suggests that middle and ingestive verbs have bieventive, causative structures. If the basic variants have co-identified arguments, and causativization delinks (or antireflexivizes) the co-identified arguments, the difference in what is entailed of the participants in the lexical and periphrastic causatives is explained. This analysis also captures the fact that the meaning differences between the two types of causatives are analogous for ingestives and middles. Additionally, the reflexive analysis presented here hints at a solution to the typological problem; transitive ingestive verbs are causativizing unexpectedly because they are not canonical transitives but are instead more like middle verbs.

While English does not have overt causativizing morphology, languages that do may show the same lexical entailment pattern. For example, Marathi has overt morphological causativization, and causativizes unaccusatives, ingestives, and middles with the same morpheme, to the exclusion of unergatives and transitives (Shibatani \& Pardeshi, 2002). The lexical entailments that hold of English dress, wash, eat and the metaphorical ingestive learn, and their lexical and periphrastic causative variants, also hold of the Marathi equivalents (Krejci, 2012), suggesting that the analysis presented here can be extended to (at least some) languages with overtly marked causatives.

\section{References}

Beck, S., \& Johnson, K. (2004). Double objects again. Linguistic Inquiry, 35(1), 97-123.

Chierchia, G. (2004). A semantics for unaccusatives and its syntactic consequences. In A. Alexiadou, E. Anagnostopoulou, \& M. Everaert (Eds.), The Unaccusativity Puzzle: Explorations of the syntax-lexicon interface (p. 288-331). Oxford: Oxford University Press.

Dowty, D. (1979). Word Meaning and Montague Grammar. Dordrecht: D. Reidel.

Horn, L. (1985). Metalinguistic negation and pragmatic ambiguity. Language, 61(1), 121-174.

Kemmer, S. (1993). The Middle Voice. Amsterdam: John Benjamins.

Koontz-Garboden, A. (2009). Anticausativization. Natural Language and Linguistic Theory, 27, 77-138.

Krejci, B. (2012). Causativization as Antireflexivization: A study of middle and ingestive verbs. Unpublished master's thesis, The University of Texas at Austin, Austin, Texas.

Rappaport Hovav, M., \& Levin, B. (1998). Building verb meanings. In M. Butt \& W. Geuder (Eds.), The Projection of Arguments: Lexical and compositional factors (p. 97-134). Stanford, CA: CSLI.

Shibatani, M. (2002). Introduction: Some basic issues in the grammar of causation. In M. Shibatani (Ed.), The Grammar of Causation and Interpersonal Manipulation (p. 1-22). Amsterdam: John Benjamins.

Shibatani, M., \& Pardeshi, P. (2002). The causative continuum. In M. Shibatani (Ed.), The Grammar of Causation and Interpersonal Manipulation (p. 85-126). Amsterdam: John Benjamins. 